\title{
A AÇÃO AFIRMATIVA DO SISTEMA DE RESERVA DE COTAS DE EMPREGO NO BRASIL COMO INSTRUMENTO DE INCLUSÃO SOCIAL DA PESSOA COM DEFICIÊNCIA
}

\author{
Leonardo Saúde Pereira ${ }^{1}$ \\ Daisy Rafaela da Silva ${ }^{2}$
}

Resumo: Este artigo trata do sistema de reserva de cotas de emprego para pessoas com deficiência como ação afirmativa imprescindível ao processo de inclusão social. O legislador pátrio instituiu no ordenamento jurídico o sistema de reserva de cotas de emprego para pessoas com deficiência no setor privado, uma espécie de ação afirmativa com o propósito de promover a igualdade de oportunidades e a inclusão social das pessoas com deficiência, art. 93 da lei $n^{\circ} 8.213 / 91$. O sistema de reserva de cotas é um instrumento para redução das desigualdades, e promoção de direitos e liberdades fundamentais e o respeito como cidadão.

Palavras-chave: Igualdade; Pessoa com deficiência; Sistema de reserva de cotas de emprego; Inclusão social.

\section{THE AFFIRMATIVE ACTION OF THE SYSTEM OF RESERVATION OF EMPLOYMENT QUOTAS IN BRAZIL AS AN INSTRUMENT OF SOCIAL INCLUSION OF THE DISABLED PERSON}

\begin{abstract}
This article deals with the system of reserving employment quotas for people with disabilities as affirmative action essential to the process of social inclusion. The national legislature established in the legal system the system of reserving employment quotas for persons with disabilities in the private sector, a kind of affirmative action with the purpose of promoting equal opportunities and social inclusion of persons with disabilities, art. 93 of Law 8213/91. The quota reservation system is an instrument for reducing inequalities, promoting fundamental rights and freedoms and respect for citizenship.
\end{abstract}

Keywords: Equality; Disabled person; Job quota reservation system; Social inclusion.

\footnotetext{
${ }^{1}$ Mestrando em Direito - Centro UNISAL Lorena SP - Contato: leosaude@hotmail.com

${ }^{2}$ Doutora em Direito. Mestre em Direitos Difusos e Coletivos. Professora Titular do Programa de Mestrado em Direito do Centro Universitário Salesiano de São Paulo (UNISAL), de Lorena/ SP e nos Cursos de Graduação e Pós-Graduaçao. Professora e Pesquisadora do Programa de Mestrado em Direito do Centro UNISAL de Lorena - SP. Professora Doutora III da EEL USP, onde ministra Legislação Ambiental e Direito aplicado à Engenharia. Contato: daisyrafa1@hotmail.com
} 


\section{INTRODUÇÃO}

A Constituição Federal de 1988 tem elevada preocupação com a ordem social, razão pela qual trouxe amplo elenco de normas, princípios e valores garantidores de direitos sociais com o escopo de diminuir as desigualdades sociais e econômicas geradas pelo Estado Liberal e pelas maiorias, e consequentemente proteger e promover a dignidade da pessoa humana.

Como mecanismo de buscar igualdade substancial, fática, adota-se então as ações afirmativas, também denominadas discriminações positivas, ou affirmative actions. Sua utilização visa corrigir as desigualdades e injustiças, oriundas até de um passado remoto, atribuindo igualdade de oportunidades a grupos e pessoas vulneráveis ou marginalizados, hipossuficientes que merecem tratamento diverso.

Como ocorre com muitas outras situações de desigualdade e hipossuficiência, a pessoa com deficiência sofreu sofreu e ainda sobre discriminação, sendo tratada de forma segregada, em muitas situações. Contudo, o tratamento atribuído à pessoa com deficiência evoluiu no decorrer da história em diversos aspectos jurídicos e sociais.

Desse modo, o legislador pátrio se preocupou em implementar no ordenamento jurídico uma espécie de ação afirmativa com o propósito de promover a igualdade de oportunidades e a inclusão social das pessoas com deficiência. Surge então o sistema de reserva de cotas de emprego para pessoas com deficiência disciplinado no art. 93 da lei $n^{\circ}$ 8.213/91, denominado por alguns como Lei de Cotas.

Através de pesquisa doutrinária, jurisprudencial, de documentos nacionais e estrangeiros e da legislação em vigor, a presente pesquisa visa demonstrar a ação afirmativa do sistema de reserva de cotas de emprego para pessoas com deficiência no setor privado como importante instrumento de inclusão social, destinado a promover a diminuição da desigualdade social e econômica e o exercício de direitos e liberdades fundamentais em condições mais iguais. Importa ressaltar que muito embora seja desejado, por se tratar de tema de grande importância no cenário social e jurídico, por óbvio não se esgotou os estudos nem se aprofundou na medida pretendida, haja vista sua amplitude. 


\section{AÇÕES AFIRMATIVAS E A IGUALDADE SUBSTANCIAL}

A Constituição Federal de 1988, deu grande importância à ordem social em seu texto - inclusive dedicou o título VIII especificamente ao tema -, elencando amplo rol de direitos sociais. Ademais, o constituinte pátrio elegeu a dignidade da pessoa humana como um dos fundamentos da República e a construção de uma sociedade livre, justa e solidária, assim como a erradicação da pobreza e da marginalização e a redução das desigualdades sociais e regionais como alguns de seus objetivos.

Tamanha preocupação com a ordem social e a positivação de normas, princípios e valores garantidores de direitos sociais têm como escopo a redução das desigualdades geradas pelo Estado Liberal, e consequentemente a proteção e promoção da dignidade da pessoa humana. Ressalta-se que com maior razão procede essa preocupação em nosso país, onde sempre teve enraizada em nossa sociedade a exclusão das minorias, portanto, devendo receber especial tratamento pelo ordenamento jurídico pátrio.

Os direitos sociais, tem como vetor a igualdade substancial. Para a concretização dos direitos fundamentais sociais consagrados no texto constitucional, mister se faz a adoção de um comportamento ativo por parte do Estado em seus Poderes, direcionando na busca da igualdade substancial ou material a condução das políticas públicas pelo administrador, a atividade do legislador, assim como a conduta do julgador no exercício da função jurisdicional.

Nesse diapasão, o constituinte pátrio trouxe no art. 5º, caput, da CF de 1988 o imprescindível princípio da igualdade, determinando que:

Todos são iguais perante a lei, sem distinção de qualquer natureza, garantindo-se aos brasileiros e aos estrangeiros residentes no País a inviolabilidade do direito à vida, à liberdade, à igualdade, à segurança e à propriedade, nos termos seguintes. (BRASIL, 1988)

Contudo, ressalta-se que não é com a mera igualdade formal que se logrará êxito na redução de desigualdades sociais, econômicas e culturais, almejadas pelos direitos fundamentais de segunda dimensão. Afirma Robert Alexy: 
Portanto, o enunciado geral de igualdade, dirigido ao legislador, não pode exigir que todos sejam tratados exatamente da mesma forma ou que todos devam ser iguais em todos os aspectos. Por outro lado, para ter algum conteúdo, ele não pode permitir toda e qualquer diferenciação e toda e qualquer distinção. É necessário questionar se e como é possível encontrar um meio-termo entre esses dois extremos. Um ponto de partida para esse meio-termo é a forma clássica: "O igual deve ser tratado igualmente, o desigual, desigualmente", que - em múltiplas variações e com inúmeras complementações - constitui a coluna vertebral da jurisprudência do Tribunal Constitucional Federal sobre o art. $3^{\circ}, 1^{\circ}$, da Constituição. (ALEXY, 2011, p. 397)

Conforme já dito, busca-se a igualdade substancial, verdadeiro vetor dos direitos sociais, analisando-se quem são os iguais e os desiguais, sendo permitidas discriminações lícitas e compatíveis com a Constituição no tratamento, justamente para que seja atendido ao supracitado princípio constitucional da isonomia.

Tema de muita importância atribuído pela doutrina diz respeito a essa discriminação lícita, também denominado discrímen legal, com vistas à concretização da igualdade substancial. Celso Antônio Bandeira de Mello elenca elementos que um discrímen deve respeitar para que não seja violador do princípio constitucional da igualdade. Assim, apresenta que:

Há ofensa ao preceito constitucional da isonomia quando:

I - A norma singulariza atual e definitivamente um destinatário determinado, ao invés de abranger uma categoria de pessoas, ou uma pessoa futura e indeterminada.

II - A norma adota como critério discriminador, para fins de diferenciação de regimes, elemento não residente nos fatos, situações ou pessoas por tal modo desequiparadas. É o que ocorre 
quando pretende tomar o fator 'tempo' - que não descansa no objeto - como critério diferencial.

III - A norma atribui tratamentos jurídicos diferentes em atenção a fator de discrímen adotado que, entretanto, não guarda relação de pertinência lógica com a disparidade de regimes outorgados.

IV - A norma supõe relação de pertinência lógica existente em abstrato, mas o discrímen estabelecido conduz a efeitos contrapostos ou de qualquer modo dissonantes dos interesses prestigiados constitucionalmente.

V - A interpretação da norma extrai dela distinções, discrímens, desequiparações que não foram professadamente assumidas por ela de modo claro, ainda que por via implícita. (MELLO, 2012, p. 4748)

Como mecanismo de alcançar a tão almejada igualdade material, fática, surge então o instituto da ação afirmativa, também denominado discriminações positivas, ou affirmative actions. Sua aplicação busca corrigir desigualdades, protegendo minorias excluídas, ou seja, certos grupos ou indivíduos vulneráveis ou marginalizados que merecem tratamento diverso com objetivo de proteção e exercício de seus direitos fundamentais de modo isonômico com os demais grupos ou indivíduos não privados da realização desses direitos e do reconhecimento como cidadão. Desse modo, o instituto tem por escopo corrigir injustiças, muitas das vezes advindas até de um passado não tão próximo, atribuindo igualdade de oportunidades a grupos e indivíduos hipossuficientes.

Marcelo Novelino traz o conceito de ações afirmativas:

As ações afirmativas consistem em políticas públicas ou programas privados desenvolvidos, em regra, com caráter temporário, visando à redução de desigualdades decorrentes de discriminações (raça, etnia) ou de uma hipossuficiência econômica (classe social) ou física (deficiência), por meio da concessão de algum tipo de vantagem compensatória de tais condições. (NOVELINO, 2013, p. 580) 
Por ser uma política que traz uma desequiparação de tratamento, muito embora seja no sentido positivo, visando a igualdade de oportunidades, e por ser voltada aos mais vulneráveis, a ação afirmativa não poderia passar imune de críticas, ainda mais por serem medidas obrigatórias, o que desagrada a agenda liberal e o poder das grandes corporações gerado pelo capitalismo desenfreado e pelos efeitos da globalização.

Contudo, diversas teorias e argumentos existem que demonstram a justiça e a imprescindibilidade dessa política afirmativa.

Dentre os argumentos mais importantes que demonstram a necessidade do instituto observa-se o fundamentado na justiça compensatória, entendendo a ação afirmativa como mecanismo de correção de desigualdades históricas, recompensando danos sofridos por grupos advindos de uma herança maldita. Esse argumento é bem aplicado no caso de discriminações positivas no tratamento de negros e índios por exemplo, sendo certo que se verifica uma dívida histórica e relação a tais grupos.

Argumento reconhecidamente aclamado e que encontra grande consonância com os objetivos do Estado Democrático de Direito e da República Federativa do Brasil (art. $3^{\circ}$ da $\mathrm{CF}$ ) baseia a ação afirmativa na justiça distributiva. Ela traz meios de distribuição de bens e recursos a grupos desfavorecidos, almejando a promoção de oportunidades iguais. Busca o atendimento ao princípio da igualdade no sentido material de acordo com o propugnado por um Estado fortemente voltado para a preocupação com as desigualdades fáticas. Demonstra ser um argumento de aceitação ampla e muito idôneo a justificar a adoção das ações afirmativas.

Outro argumento favorável às discriminações positivas procura demonstrar a importância das referidas políticas na proteção do pluralismo, da diversidade. As políticas afirmativas valorizam e fomentam o pluralismo, promovem o respeito aos direitos fundamentais de todos segmentos sociais, principalmente das minorias excluídas. Jürgen Habermas em sua teoria do discurso coloca a proteção ao debate plural como condição essencial ao Estado Democrático de Direito, sendo as ações afirmativas adotadas como mecanismos íntegros de inclusão e da valorização da diversidade. Esse argumento também possui íntima compatibilidade com os objetivos fundamentais da República Federativa do Brasil, valendo frisar que o pluralismo se constitui em um dos seus fundamentos (art. $1^{\circ}, \mathrm{V}$, da CF). 
Por fim, não se poderia deixar de mencionar as consagradas teoria do reconhecimento, de Axel Honneth, e teoria da redistribuição, reconhecimento e representação, de Nancy Fraser, desenvolvidas por esses ilustres estudiosos do tema, que tratam de forma ampla e especial a utilização das ações afirmativas, razão pela qual apenas se permite ressaltar sua importância.

No Brasil, após intenso debate sobre a constitucionalidade da adoção de ações afirmativas, o tema chegou ao Supremo Tribunal Federal, que posicionou-se de forma favorável a tais medidas viabilizadoras da igualdade substancial. Uma decisão proferida pelo guardião da Constituição referente ao tema ocorreu na ADPF 186 apresentada pelo Partido Democratas que pretendia ver declarada a inconstitucionalidade do sistema de cotas étnicoraciais criado na Universidade de Brasília, que reservava vagas para ingresso de estudantes negros e indígenas. Por unanimidade foi julgada improcedente pelo STF:

ADPF 186, Relator(a): Min. RICARDO LEWANDOWSKI, Tribunal Pleno, julgado em 26/04/2012, ACÓRDÃO ELETRÔNICO DJe-205 DIVULG 17-10-2014 PUBLIC 20-102014

Ementa: ARGUIÇÃO DE DESCUMPRIMENTO DE PRECEITO FUNDAMENTAL. ATOS QUE INSTITUÍRAM SISTEMA DE RESERVA DE VAGAS COM BASE EM CRITÉRIO ÉTNICORACIAL (COTAS) NO PROCESSO DE SELEÇÃO PARA INGRESSO EM INSTITUIÇÃO PÚBLICA DE ENSINO SUPERIOR. ALEGADA OFENSA AOS ARTS. $1^{\circ}$, CAPUT, III, $3^{\circ}$, IV, 4 ${ }^{\mathrm{o}}$, VIII, 5 , I, II XXXIII, XLI, LIV, 37, CAPUT, 205, 206, CAPUT, I, 207, CAPUT, E 208, V, TODOS DA CONSTITUIÇÃO FEDERAL. AÇÃO JULGADA IMPROCEDENTE. I - Não contraria - ao contrário, prestigia - o princípio da igualdade material, previsto no caput do art. $5^{\circ}$ da Carta da República, a possibilidade de o Estado lançar mão seja de políticas de cunho universalista, que abrangem um número indeterminados de indivíduos, mediante ações de natureza estrutural, seja de ações 
afirmativas, que atingem grupos sociais determinados, de maneira pontual, atribuindo a estes certas vantagens, por um tempo limitado, de modo a permitir-lhes a superação de desigualdades decorrentes de situações históricas particulares. II - O modelo constitucional brasileiro incorporou diversos mecanismos institucionais para corrigir as distorções resultantes de uma aplicação puramente formal do princípio da igualdade. III - Esta Corte, em diversos precedentes, assentou a constitucionalidade das políticas de ação afirmativa. IV Medidas que buscam reverter, no âmbito universitário, o quadro histórico de desigualdade que caracteriza as relações étnico-raciais e sociais em nosso País, não podem ser examinadas apenas sob a ótica de sua compatibilidade com determinados preceitos constitucionais, isoladamente considerados, ou a partir da eventual vantagem de certos critérios sobre outros, devendo, ao revés, ser analisadas à luz do arcabouço principiológico sobre o qual se assenta o próprio Estado brasileiro. V-Metodologia de seleção diferenciada pode perfeitamente levar em consideração critérios étnico-raciais ou socioeconômicos, de modo a assegurar que a comunidade acadêmica e a própria sociedade sejam beneficiadas pelo pluralismo de ideias, de resto, um dos fundamentos do Estado brasileiro, conforme dispõe o art. $1^{\circ}$, V, da Constituição. VI - Justiça social, hoje, mais do que simplesmente redistribuir riquezas criadas pelo esforço coletivo, significa distinguir, reconhecer e incorporar à sociedade mais ampla valores culturais diversificados, muitas vezes considerados inferiores àqueles reputados dominantes. VII - No entanto, as políticas de ação afirmativa fundadas na discriminação reversa apenas são legítimas se a sua manutenção estiver condicionada à persistência, no tempo, do quadro de exclusão social que lhes deu origem. Caso contrário, tais políticas poderiam converter-se benesses permanentes, instituídas em prol de determinado grupo social, mas em detrimento da coletividade como um todo, situação - é escusado dizer - incompatível com o espírito 
de qualquer Constituição que se pretenda democrática, devendo, outrossim, respeitar a proporcionalidade entre os meios empregados e os fins perseguidos. VIII - Arguição de descumprimento de preceito fundamental julgada improcedente.

Percebe-se que a política ou sistema de cotas se constitui em uma das espécies das ações afirmativas, sendo certo que o constituinte de 1988 fez clara opção por seu manejo na busca pela eliminação ou ao menos redução das desigualdades, direcionando-se pela via da inclusão social dos menos favorecidos. A título de exemplo de ações afirmativas adotadas pela Carta Maior cita-se a reserva de cotas para pessoas com deficiência em cargo e emprego público (art. 37, VIII, da CF), os incentivos específicos na proteção do trabalho da mulher (art. $7^{\circ}, \mathrm{XX}$, da $\mathrm{CF}$ ), além de diversas outras regras e princípios que clamam pela adoção das discriminações positivas.

Aliás, em se tratando de pessoas com deficiência, cumpre salientar que a utilização de ações afirmativas em seu favor ocorre em obediência até a uma convenção internacional de grande importância mundial, a Convenção Sobre os Direitos das Pessoas com Deficiência da ONU de 2006, que inclusive foi recebida no ordenamento jurídico com equivalência de emenda constitucional, consoante o disposto no $\S 3^{\circ}$ do art. $5^{\circ}$ da $\mathrm{CF}$, com a redação dada pela Emenda Constitucional n ${ }^{\circ} 45$ de 2004.

Vale destacar que a adoção de uma ação afirmativa, via de regra, deve ocorrer durante um certo período, não sendo uma medida definitiva, devendo a política adotada ser extinta com o atingimento dos objetos visados. Contudo, essa característica da temporariedade em sua utilização não se aplicará em alguns casos peculiares, embora não seja unânime, como na hipótese específica de sistema de reserva de cotas e outras ações afirmativas voltadas para o benefício de pessoas com deficiência.

\section{O TRATAMENTO DA PESSOA COM DEFICIÊNCIA (PCD)}

O tratamento dedicado à pessoa com deficiência evoluiu no decurso da história da humanidade, em diversos aspectos, seja no que tange à disciplina jurídica, bem como ao 
tratamento social, sem se olvidar inclusive da própria nomenclatura atribuída à pessoa que se encontra nessa situação e sua conceituação.

Como ocorre com outras tantas situações de vulnerabilidade, a pessoa com deficiência sofreu discriminação no passado, sendo tratada de forma segregada, com atrocidades e até sendo exterminadas. A postura de eliminação de pessoas com deficiência ocorreu mais comumente entre os povos primitivos, mas também não deixou de existir na Idade Média e até em passado próximo, como se verificou em governos fascistas do século XX, como o nazismo de Hitler.

Contudo, somente após a segunda guerra mundial, com a valorização da dignidade da pessoa humana, que se passou a tratar a pessoa com deficiência sem o estigma de doente, sendo a deficiência mais uma situação dentro do universo plural que vivemos. Assim, passa a pessoa com deficiência a ser tratada de forma isonômica (igualdade material), com vistas a sua inclusão social, sendo mister sua inserção no mercado de trabalho.

A evolução no tratamento foi tão grande que no decorrer dos últimos anos se vislumbra mudanças na terminologia empregada pelas normas para se referirem a quem possua alguma deficiência. Atualmente, o termo técnico empregado é pessoa com deficiência (PCD), que foi utilizado pela Convenção Sobre os Direitos das Pessoas com Deficiência da ONU de 2006 e mantido pelo Estatuto da Pessoa com Deficiência. Terminologia elogiável pela doutrina, pois evita confundir deficiência com doença, que ocorre quando se adota a expressão pessoa portadora de deficiência, que é usada no texto constitucional de 1988. Outrossim, se demonstra melhor que o termo pessoa com necessidades especiais, que é um termo genérico, que pode ser atribuído a outras pessoas que não possuam deficiência, como gestantes, idosos.

Como se verifica, na atualidade a importância atribuída ao devido tratamento da pessoa com deficiência é ímpar, o que se vislumbra especialmente com a existência de diversos documentos normativos sobre o tema. Destaca-se no âmbito da Organização Internacional do Trabalho (OIT) a Convenção $n^{0} 159$ e a Recomendação $n^{0} 168$, ambas de 1983, que se referem diretamente ao trabalho da pessoa com deficiência.

O documento internacional que se constitui no marco da promoção da inclusão da pessoa com deficiência é a já citada Convenção Sobre os Direitos das Pessoas com Deficiência da ONU de 2006, que foi recepcionada com equivalência de emenda constitucional pelo ordenamento jurídico pátrio, e propugna de forma expressa pela adoção 
de ações afirmativas para a promoção de pessoas com deficiência no mercado de trabalho. Insta observar que a referida Convenção da ONU passou a adotar o modelo da Classificação Internacional de Funcionalidades, Incapacidade e Saúde (CIF) para o trato das deficiências, em complemento ao modelo estritamente médico do Código Internacional de Doenças e de Problemas Relacionados à saúde (CID), o que denota a nítida preocupação com a efetiva inclusão social da pessoa com deficiência.

No Brasil, nossa Constituição Federal, tem em seu bojo a promoção da igualdade substancial das pessoas em situação de fragilidade já prevê a reserva de cargos e empregos públicos para pessoas com deficiência (art. 37, VIII, da CF). Na mesma toada, o constituinte fez questão de proibir de forma expressa qualquer discriminação no tocante a salário e critérios de admissão do trabalhador com deficiência (art. $7^{\circ}, \mathrm{XXXI}$, da CF).

Cabe frisar ainda a lei $\mathrm{n}^{\mathrm{0}} 7.853 / 89$ e o decreto $\mathrm{n}^{\mathrm{0}} 3.298 / 99$ - regulamentou a referida lei -,que trouxeram muitos benefícios em prol da pessoa com deficiência. Ademais, por óbvio imperioso ressaltar a aclamada lei $\mathrm{n}^{0} 13.146 / 2015$, denominada Estatuto da Pessoa com Deficiência, que veio para consolidar a busca pela inclusão social da pessoa com deficiência, sendo extraído de seu art. $2^{\circ} \mathrm{o}$ atual conceito de pessoa com deficiência:

Art. $2^{\circ}$ Considera-se pessoa com deficiência aquela que tem impedimento de longo prazo de natureza física, mental, intelectual ou sensorial, o qual, em interação com uma ou mais barreiras, pode obstruir sua participação plena e efetiva na sociedade em igualdade de condições com as demais pessoas.

Tratando especificamente do tema em estudo, nosso ordenamento jurídico possui o art. 93 da lei $n^{\circ} 8.213 / 91$, chamado por alguns por Lei de Cotas, que disciplina o sistema de reserva de cotas de emprego, e assim dispõe, após algumas alterações advindas da lei $\mathrm{n}^{\mathrm{o}}$ 13.146/2015:

Art. 93. A empresa com 100 (cem) ou mais empregados está obrigada a preencher de $2 \%$ (dois por cento) a $5 \%$ (cinco por cento) 
dos seus cargos com beneficiários reabilitados ou pessoas portadoras de deficiência, habilitadas, na seguinte proporção:

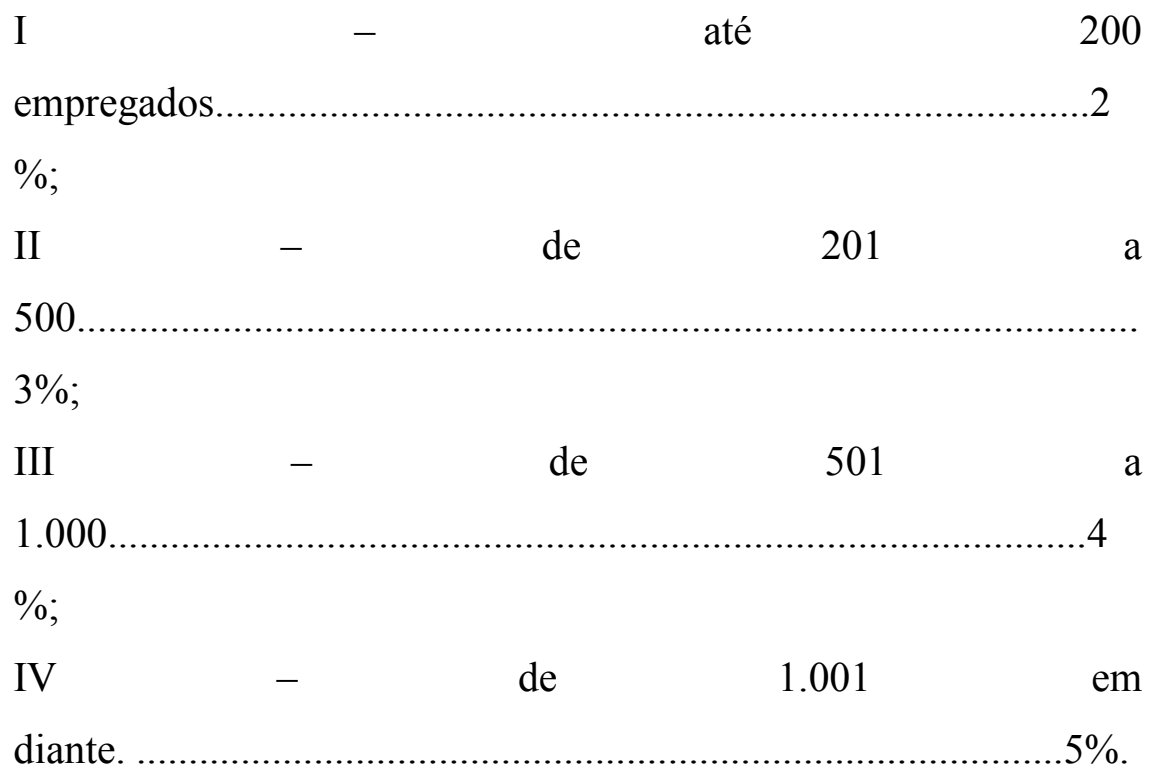

V - (VETADO). (Incluído pela Lei no 13.146, de 2015)

$\S 1^{\mathrm{o}}$ A dispensa de pessoa com deficiência ou de beneficiário reabilitado da Previdência Social ao final de contrato por prazo determinado de mais de 90 (noventa) dias e a dispensa imotivada em contrato por prazo indeterminado somente poderão ocorrer após a contratação de outro trabalhador com deficiência ou beneficiário reabilitado da Previdência Social. (Redação dada pela Lei nº 13.146, de 2015)

$\S 2^{\circ}$ Ao Ministério do Trabalho e Emprego incumbe estabelecer a sistemática de fiscalização, bem como gerar dados e estatísticas sobre o total de empregados e as vagas preenchidas por pessoas com deficiência e por beneficiários reabilitados da Previdência Social, fornecendo-os, quando solicitados, aos sindicatos, às entidades representativas dos empregados ou aos cidadãos interessados. (Redação dada pela Lei no 13.146 , de 2015)

$\S 3^{\circ}$ Para a reserva de cargos será considerada somente a contratação direta de pessoa com deficiência, excluído o aprendiz com deficiência de que trata a Consolidação das Leis do Trabalho (CLT), 
aprovada pelo Decreto-Lei no 5.452, de 1o de maio de 1943. (Incluído pela Lei ${ }^{\circ} 13.146$, de 2015)

$\S 4^{\circ}$ (VETADO) (Incluído pela Lei n ${ }^{\circ} 13.146$, de 2015).

Conforme já elucidado, o sistema de reserva de cotas de emprego é uma ação afirmativa, adotada por diversos países, e que vem recebendo cada vez mais atenção no Brasil no cenário atual, tendo em vista sua eficiência em promover o exercício de direitos e liberdades fundamentais pela pessoa com deficiência e seu repeito como cidadão, caso concretizado em conjunto com outras políticas afirmativas inclusivas.

\section{A IMPORTÂNCIA DO SISTEMA DE RESERVA DE COTAS DE EMPREGO NO BRASIL PARA A INCLUSÃO SOCIAL DA PCD}

A CF de 1988 rompeu com o modelo assistencialista e instituiu o modelo inclusivo de tratamento da pessoa com deficiência no Brasil, fazendo com que o Estado passasse a implementar políticas afirmativas e constituísse um arcabouço jurídico voltado para esse modelo atual proposto pelo constituinte.

O trabalho, com seu valor social reconhecido como fundamento de nossa República, se constitui em um dos meios aptos a construir uma sociedade mais livre, justa e solidária e a reduzir as desigualdades sociais, sendo, portanto, instrumento imprescindível de inclusão social das pessoas com deficiência, proporcionando-lhes o necessário convívio com a sociedade.

Destarte, como forma de garantir a igualdade de oportunidades no mercado de trabalho do setor privado, e atento à importância do trabalho para propiciar a inclusão social, o legislador pátrio através do art. 93 da lei $n^{\circ} 8.213 / 91$ estabeleceu reserva de cotas de emprego para PCDs nas empresas que possuem a partir de cem empregados, consoante o texto do referido dispositivo acima transcrito.

Vale frisar que apenas será considerada para a reserva de cotas a contratação diretamente realizada pela empresa de PCD, não computando a efetuada por meio de terceirização, conforme preceitua o $\S 3^{\circ}$ do retromencionado art. 93, incluído pelo festejado 
Estatuto da Pessoa com Deficiência, que também exclui o aprendiz, mesmo com deficiência, que já possui reserva de cotas específica.

Cabe salientar que o Estatuto da Pessoa com Deficiência estabelece em seu art. 104 que poderá ser dada preferência nos processos de licitação para bens e serviços produzidos ou prestados por empresas que comprovem o cumprimento da referida reserva de cotas para pessoas com deficiência ou para reabilitados da Previdência Social prevista no art. 93 da lei $\mathrm{n}^{\mathrm{o}} 8.213 / 91$ e que atendam às regras de acessibilidade previstas na legislação, devendo as empresas cumprirem, durante todo o período de execução do contrato, tais requisitos legais de preferência.

$\mathrm{O} \S 1^{\circ}$ do art. 93 ora analisado traz uma regra de suma importância para o êxito dos propósitos de inserção da PCD no mercado de trabalho. Ele determina que para que se ocorra dispensa de PCD ou de beneficiário reabilitado da Previdência Social que tenham sidos contratados por prazo determinado superior a noventa dias, ou por prazo indeterminado, no caso de dispensa imotivada, deverão ser respeitadas duas condições de modo cumulativo: contratação de outro trabalhador com deficiência ou beneficiário reabilitado da Previdência Social e que seja respeitada a cota descrita no caput do art. 93. Caso contrário, caberá ao empregado dispensado sem respeito por parte da empresa aos requisitos legais o direito de pedir reintegração com todas suas consequências legais, e, em caso de incompatibilidade de convivência com o empregador, fará jus à indenização substitutiva. Portanto, da análise do $\S 1^{\circ}$ do art. 93 extrai-se uma espécie de estabilidade no emprego a PCD ou beneficiário reabilitado da Previdência Social, que enfatiza a preocupação do legislador em mantê-las efetivamente no mercado de trabalho. Assim, tem a Justiça do Trabalho realçado essa limitação ao direito potestativo de despedir do empregador:

RR - 1462-95.2014.5.12.0016, Relatora Ministra: Delaíde Miranda Arantes, Data de Julgamento: 15/03/2017, $2^{\text {a }}$ Turma, Data de Publicação: DEJT 31/03/2017

RECURSO DE REVISTA INTERPOSTO NA VIGÊNCIA DA LEI 13.015/2014. DISPENSA. EMPREGADO COM DEFICIÊNCIA. NÃO OBSERVÂNCIA DOS REQUISITOS DO ART. 93, CAPUT E $\S 1^{\circ}{ }^{\circ}$, DA LEI 8.213/91. REINTEGRAÇÃO. A legislação previdenciária, no intuito de dar efetividade à garantia constitucional 
de proteção ao empregado portador de deficiência, condicionou, por meio do art. 93, $\S 1 .^{\circ}$, da Lei 8.213/91, a dispensa do trabalhador reabilitado ou deficiente habilitado à contratação de substituto que tenha condição semelhante. Referido dispositivo encerra verdadeira limitação ao direito potestativo de despedir, razão pelo qual, uma vez não observado pelo empregador a exigência nele constante, é devido o retorno do trabalhador ao emprego. Precedentes de todas as Turmas desta Corte. Recurso de revista não conhecido.

Ressalta-se que o tratamento diferenciado se deve ao fato dos obstáculos e exclusão que sobrevêm às pessoas com deficiência em um mercado de trabalho cada vez mais competitivo. Dessa forma, nada mais justo e necessário que a implementação do sistema de reserva de cotas de emprego no setor privado, que se constitui em uma espécie de ação afirmativa com a finalidade de promover a igualdade de oportunidades, buscando a proteção e exercício de direitos fundamentais pela PCD.

Por ser medida coercitiva e contrária ao interesse de grandes empresas e até de certas maiorias não beneficiadas, essa valorosa política afirmativa sofre algumas críticas infundadas, principalmente por parte desses setores contrariados. Observa-se algumas críticas como a carência de PCDs qualificadas para o trabalho, despesas por parte das empresas para contratação de PCDs, e até que essa ação afirmativa violaria direito das pessoas sem deficiência, e que geraria aumento da discriminação em relação à PCD.

Contudo, existem estudos que demonstram não serem altos os custos contratação de PCDs. Ademais, as PCDs sempre sofreram discriminação e exclusão, sendo a inserção delas no mercado de trabalho um meio de permitir a elas acabarem com esse preconceito em relação a eventual falta de capacidade de desempenharem uma atividade laboral. Outrossim, nunca é demais lembrar, consta na Convenção Sobre os Direitos das Pessoas com Deficiência da ONU de 2006, ratificada pelo Brasil, o compromisso expresso de implementar ações afirmativas em prol das pessoas com deficiência.

Lutiana Nacur Lorentz, defensora do sistema de cotas de emprego, tece alguns apontamentos para seu aperfeiçoamento: 
[...] assevera-se a necessidade de combinação do sistema de quotas de trabalho a outros de acessibilidade ambiental, arquitetônico, de meio ambiente de trabalho inclusivo, bem como a sistemas premiativos de contratação, sobretudo o de ajuda-adaptação e redução ou até isenção de tributos, e que também deve haver uma política inclusiva devidamente planejada, avaliada e executada junto às associações de pessoas com deficiência, aos órgãos de estatísticas, com educação inclusiva e programas de qualificação de PCDs tanto para o trabalho quanto para melhoria de sua qualificação e com vistas aos propósitos de sua real independência e inclusão social. (LORENTZ, 2016, p. 218)

O Ministério do Trabalho recebeu duas atribuições do $\S 2^{\circ}$ do art. 93. O dispositivo em tela disciplinou que cabe a ele gerar dados e estatísticas sobre o total de empregados e as vagas preenchidas por pessoas com deficiência e por beneficiários reabilitados da Previdência Social, fornecendo-os, quando solicitados, aos sindicatos, às entidades representativas dos empregados ou aos cidadãos interessados, assim como está incumbido de estabelecer a sistemática de fiscalização do cumprimento da referida reserva de cotas.

Outro órgão que exerce importante papel de fiscalização, fundamental para a efetividade do sistema de cotas de emprego, é o Ministério Público do Trabalho. Lutiana Nacur Lorentz faz uma interessante abordagem no que tange ao destino de multas e indenizações auferidas em sede de ação civil pública:

[...] o que vem ocorrendo na prática do atual sistema é que: se, de um lado, o Ministério Público do Trabalho tem se empenhado em fazer cumprir a regra do art. 93 da Lei $n^{\circ} 8.213$, de 24 julho de 1991 (apesar de, quase nunca a pessoa com deficiência saber que foi contratada por ação do MPT, que assim atua como uma "mão invisível”), por outro, amiúde, nas ações civis públicas ajuizadas neste sentido a indenização por descumprimento da lei (ou da obrigação de fazer, imposta pelo poder judiciário) é revertida em prol do Fundo de Amparo ao Trabalhador ou Fundo de Direitos 
Difusos e não diretamente às pessoas com deficiência ou às suas associações. Uma alternativa seria a criação de um fundo específico para amealhar recursos para portadores de deficiência com gestao tripartite, ou mesmo de cinco entidades (governo, entidades de defesa das pessoas com deficiência, empresários, sindicatos e Ministérios Públicos), o Fundo de Inclusão das Pessoas com Deficiência ao qual deveria ser revertido o numerário advindo de qualquer descumprimento da legislação afeta ao tema, devendo estes valores ser revertidos, entre outras coisas, para educação das PCDs, para sua habilitação e reabilitação, para remoção de barreiras, pagamento de ajuda-adaptação, redução de tributos e ajuda à saúde das mesmas. (LORENTZ, 2016, p. 215216, grifo do autor)

Assim, vem aumentando o número de pessoas com deficiência no mercado de trabalho formal. Conforme informações publicadas em 27 de setembro de 2016 no sítio do Portal Brasil, que cita como fonte o Ministério do Trabalho, 403,2 mil pessoas trabalham formalmente (RAIS 2015). Consta ainda que quase $24 \%$ da população brasileira é composta por pessoas que possuem algum tipo de deficiência, o que dá em torno de 45 milhões de pessoas com algum tipo de deficiência no Brasil (CENSO IBGE). Em 2015, o número de empregos para as pessoas com deficiência cresceu 5,75\% em relação ao ano de 2014. Ressalta-se que consta a informação de que em 2015 foram mais de 4,5 mil autuações fiscais por descumprimento da Lei de Cotas (Portal Brasil, com informações do Ministério do Trabalho, publicado em 27/09/2016).

Nessa esteira, Ivana Aparecida Grizzo Ragazzi enfatiza o papel do Estado e das autoridades competentes para a concretização do acesso ao mercado de trabalho pela pessoa com deficiência:

[...] o Estado deve materializar as leis existentes para lhes conceder oportunidades de trabalho, fazendo isso, desde a simples prática de modificação e adaptação do meio social, transpondo barreiras, para que tenham acesso ao trabalho, à escola, ao teatro, enfim, a todos 
os segmentos sociais, para que de excluidas passem a ser incluidas, bem como exigindo, por meio dos órgãos competentes, o cumprimento das normas existentes. (RAGAZZI, 2010, p. 121, grifo do autor)

Não se pode olvidar que o uso da tecnologia cada vez mais evoluída contribui bastante para as adaptações necessárias ao exercício do labor pela PCD, tanto no ambiente de trabalho como em relação à acessibilidade, facilitando o cumprimento da Lei de Cotas.

\section{CONSIDERAÇÕES FINAIS}

Não há dúvidas de que o sistema de reserva de cotas de emprego no setor privado é essencial para a legítima inclusão social da pessoa com deficiência, ainda mais em um mercado de trabalho cada vez competitivo e excludente que vivenciamos. O trabalho é imprescindível para o pleno exercício da cidadania, dignifica o ser. Além de permitir uma vida mais independente e digna, possibilitando a própria subsistência, o exercício do labor pela pessoa com deficiência inclui ela no necessário convívio no social, rompendo com as barreiras da discriminação.

O objetivo dessa ação afirmativa não podia ser diferente como instrumento de viabilização do princípio da igualdade substancial que é. De um passado de segregação até o atual estágio de adoção de um sistema de inclusão o caminho foi árduo para as pessoas com deficiência, e as lições da história não devem esquecidas.

A Lei de Cotas, consubstanciada no art. 93 da lei $n^{0} 8.213 / 91$, necessita do comprometimento do Estado e seus órgãos e autoridades competentes, assim como de toda sociedade, inclusive das empresas empregadoras, para seu efetivo cumprimento. Os instrumentos e regras foram bem disciplinados. Contudo, por óbvio mister se faz que seja adotada, planejada e avaliada com outras políticas inclusivas conjuntamente, como educação inclusiva, qualificação e reabilitação para sua maior eficiência em promover o exercício de direitos e liberdades fundamentais pela pessoa com deficiência e seu repeito como cidadão.

Deve-se desmistificar qualquer sentimento contrário à potencialidade da pessoa com deficiência e exterminar de forma definitiva a discriminação. As oportunidades já dadas às pessoas com deficiência pela Lei de Cotas de inserção no mercado de trabalho têm 
confirmado sua capacidade de exercício do labor, sendo muita das vezes trabalhadores mais competentes e responsáveis do que pessoas sem deficiência.

O Estado Democrático de Direito, fundado na dignidade da pessoa humana, zela pelo respeito à diversidade e pela inclusão social, e a ação afirmativa do sistema de reserva de cotas de emprego para pessoa com deficiência, sem sombra de dúvidas, é um condutor bem orientado no caminho da redução das desigualdades.

\section{REFERÊNCIAS}

ALEXY, Robert. Teoria dos direitos fundamentais. Tradução de Virgílio Afonso da Silva. 2. ed. São Paulo: Malheiros, 2011.

BARROSO, Luís Roberto. Curso de direito constitucional contemporâneo: os conceitos fundamentais e a construção do novo modelo. 3. ed. São Paulo: Saraiva, 2011.

BRANCO, Paulo Gustavo Gonet; MENDES, Gilmar Ferreira. Curso de direito constitucional. 9. ed. São Paulo: Saraiva, 2014.

BULOS, Uadi Lammêgo. Curso de direito constitucional. 4. ed. São Paulo: Saraiva, 2009.

BRASIL. Constituição da República Federativa do Brasil. Diário Oficial [da] República Federativa do Brasil, Poder Executivo, Brasília, DF, 05 out. 1988.

Lei $n^{\circ} 8.213$, de 24 de julho de 1991. Dispõe sobre os Planos de Benefícios da Previdência Social e dá outras providências. Diário Oficial [da] República Federativa do Brasil, Poder Executivo, Brasília, DF, 25 jul. 1991.

. Lei n ${ }^{\circ} 13.146$, de 06 de julho de 2015. Institui a Lei Brasileira de Inclusão da Pessoa com Deficiência (Estatuto da Pessoa com Deficiência). Diário Oficial [da] República Federativa do Brasil, Poder Executivo, Brasília, DF, 07 jul. 2015.

Supremo Tribunal Federal. ADPF 186/DF. Requerente: Democratas - DEM. Relator: Ministro Ricardo Lewandowski. Brasília, 26 de abril de 2012. Disponível em: $<$ http://www.stf.jus.br/portal/jurisprudencia/visualizarEmenta.asps1=000249991\&ba se=baseAcordaos $>$. Acesso em: 08 abr. 2017.

Tribunal Superior do Trabalho. RR - 1462-95.2014.5.12.0016. Recorrente: Tupy S.A. Recorrido: Nelson Mafra. Relatora Ministra: Delaíde Miranda Arantes. Brasília, 15 de março de 2017.2 Disponível em: $<$ http://aplicaca05.tst.jus.br/consultaunificada2/inteiroTeor.do?action=printInteiroTe or\&format $=$ html\&highlight=true\&numeroFormatado=RR\%20-\%201462- 
95.2014.5.12.0016\&base $=$ acordao\&rowid=AAANGhAAFAABAzcAAK\&dataPublica $\mathbf{c a o}=31 / 03 / 2017 \&$ localPublicacao $=$ DEJT\&query $=$ defici\%EAncia\%20and\%20cotas $>$. Acesso em: 28 abr. 2017.

BONAVIDES, Paulo. Curso de direito constitucional. 26. ed. São Paulo: Malheiros, 2011.

CANOTILHO, José Joaquim Gomes. Direito constitucional e teoria da constituição. 7. ed. Coimbra: Almedina, 2003.

CISZEWSKI, Ana Claudia Vieira de Oliveira. O trabalho da pessoa portadora de deficiência. São Paulo: LTr, 2005.

GARCIA, Gustavo Filipe Barbosa. Curso de direito do trabalho. 8. ed. Rio de Janeiro: Forense, 2014.

GOLDFARB, Cibelle Linero. Pessoas portadoras de deficiência e a relação de emprego: o sistema de cotas no Brasil. Curitiba: Juruá, 2007.

HABERMAS, Jürgen. Direito e democracia: entre facticidade e validade. Tradução de Flávio Beno Siebeneichler. Rio de Janeiro: Tempo Brasileiro, 1997. v. 1.

LENZA, Pedro. Direito constitucional esquematizado. 17. ed. São Paulo: Saraiva, 2013.

LORENTZ, Lutiana Nacur. A norma da igualdade e o trabalho das pessoas com deficiência. 2. ed. São Paulo: LTr, 2016.

MELLO, Celso Antônio Bandeira de. O conteúdo jurídico do princípio da igualdade. 3. ed. São Paulo: Malheiros, 2012.

NOVELINO, Marcelo. Manual de direito constitucional. 8. ed. Rio de Janeiro: Forense; São Paulo: Método, 2013.

PORTAL BRASIL. Cresce número de pessoas com deficiência no mercado de trabalho formal. 27 set. de 2016. Disponível em: <http://www.brasil.gov.br/economia-eemprego/2016/09/cresce-numero-de-pessoas-com-deficiencia-no-mercado-de-trabalhoformal>. Acesso em: 13 abr. 2017.

RAGAZZI, Ivana Aparecida Grizzo. Inclusão social: a importância do trabalho da pessoa portadora de deficiência. São Paulo: LTr, 2010.

RAMPAZZO, Lino. Metodologia científica: para alunos dos cursos de graduação e pósgraduação. 8. ed. São Paulo: Loyola, 2015.

SANTOS, Marisa Ferreira dos. Direito previdenciário esquematizado. 6. ed. São Paulo: Saraiva, 2016. 
SARLET, Ingo Wolfgang. Dignidade (da pessoa) humana e direitos fundamentais na Constituição Federal de 1988. 10. ed. Porto Alegre: Livraria do Advogado, 2015.

SILVA, José Afonso da. Curso de direito constitucional positivo. 34. ed. São Paulo: Malheiros, 2011. 